\title{
Espécies de Cladonia com cifas não verticiladas do Supergrupo Cladonia em ambientes de altitude da Serra do Mar no Sul do Brasil ${ }^{1}$
}

\author{
Ana Marcia Charnei ${ }^{2,3}$ e Sionara Eliasaro ${ }^{2}$
}

Recebido: 21.01.2014; aceito: 21.03.2014

\begin{abstract}
Cladonia species with no verticillate scyphi of the Cladonia Supergroup from high-altitude environments in the Serra do Mar Mountain in southern Brazil). In a survey of species of Cladonia occurring in high-altitude environments at Serra do Mar Mountain in southern Brazil, 11 species with no verticillate scyphi of the Cladonia Supergroup were found, of which C. multiformis is recorded for the first time in South America, C. pyxidata is new to states of Paraná and Santa Catarina, and C. chlorophaea, C. grayi and C. polyscypha to Paraná State. We present an identification key, descriptions, comments and illustrations.
\end{abstract}

Keywords: Lichenized fungi, Paraná State, Santa Catarina State, taxonomy

RESUMO - (Espécies de Cladonia com cifas não verticiladas do Supergrupo Cladonia em ambientes de altitude da Serra do Mar no Sul do Brasil). Em um levantamento das espécies de Cladonia ocorrentes em ambientes de altitude da Serra do Mar no Sul do Brasil foram encontradas 11 espécies de Cladonia com cifas não verticiladas do Supergrupo Cladonia. Dentre estas, C. multiformis é registrada pela primeira vez na América do Sul, C. pyxidata é nova ocorrência para os Estados do Paraná e Santa Catarina, e C. chlorophaea, C. grayi e C. polyscypha para o Estado do Paraná. São apresentadas chave de identificação, descrições, comentários e ilustrações.

Palavras-chave: Estado do Paraná, Estado de Santa Catarina, Fungos liquenizados, taxonomia

\section{Introdução}

Neste trabalho é dada continuidade a uma série de estudos referentes às espécies de Cladoniaceae que ocorrem em ambientes de altitude da Serra do Mar no Sul do Brasil (Charnei \& Eliasaro 2013a, b). Todas as espécies apresentadas são do Supergrupo Cladonia (Stenroos et al. 2002) e possuem como características em comum, além da produção de ácido fumarprotocetrárico, o ápice do podécio em forma de taças que não se ramificam a partir do centro (Ahti 2000), denominadas cifas não verticiladas.

A formação de cifas não verticiladas também é encontrada em espécies do Supergrupo Cocciferae. No entanto, nas espécies do Supergrupo Cladonia não há produção de depsídios e dibenzofuranos, e as depsidonas são frequentemente os principais compostos secundários (Stenroos et al. 2002, Burgaz \& Ahti 2009).
Dentre as 12 espécies de Cladonia com podécio cifoso e não verticilado do Supergrupo Cladonia registradas para o Sul do Brasil (Fleig et al. 1995, Ahti 2000, Eliasaro et al. 2012, Gumboski \& Eliasaro 2011, Gumboski et al. 2013), apenas C. furfuracea Vain. é citada para a Serra do Mar paranaense e não há qualquer registro para a Serra do Mar de Santa Catarina.

\section{Material e métodos}

A área de estudo abrange os municípios de Campina Grande do Sul, Morretes, Piraquara, Quatro Barras e Guaratuba no Estado do Paraná e Garuva, Campo Alegre, Joinville e Santo Amaro da Imperatriz no Estado de Santa Catarina. Os dados geográficos e climáticos são descritos em Charnei \& Eliasaro (2013b). Após secos em temperatura ambiente ou em estufa a baixa temperatura, os materiais foram

1. Parte da Dissertação de Mestrado da primeira Autora

2. Universidade Federal do Paraná, Departamento de Botânica, Laboratório de Liquenologia, Caixa Postal 19301, 81531-970 Curitiba, PR, Brasil

3. Autor para correspondência: acharnei@yahoo.com.br 
herborizados e incorporados ao Herbário UPCB da Universidade Federal do Paraná. Também foram estudados espécimes dos herbários ICN e MBM. As análises morfológicas foram realizadas sob microscópio estereoscópico $(20-50 \times)$ e para as análises anatômicas, cortes feitos à mão livre, foram observados sob microscópio óptico (400-1000×), ambos com ocular munida de retículo graduado. Para a identificação de metabólitos secundários de importância taxonômica foram utilizados testes de coloração de córtex e medula, observação do talo sob lâmpada UV (Taylor 1967, 1968) e cromatografia em camada delgada (CCD) seguindo Culberson \& Ammann (1979) e Elix \& Ernst-Russell (1993).

\section{Resultados e Discussão}

Foram encontradas 11 espécies de Cladonia com cifas não verticiladas do Supergrupo Cladonia em ambientes de altitude da Serra do Mar no Sul do Brasil. Cladonia chlorophaea (Flörke ex Sommerf.) Spreng. e C. ramulosa (With.) J. R. Laundon foram encontradas apenas no Estado do Paraná, enquanto C. furfuracea, C. grayi G. Merrill ex Sandstede, C. multiformis G. Merr., C. ochracea L. Scriba, C. ochrochlora Flörke, C. polyscypha Ahti \& Xavier Filho, C. pyxidata (L.) Hoff., C. ramulosa (With.) J. R. Laundon, C. subradiata (Vain.) Sands. e C. subsquamosa Kremp. ocorreram nos Estados do Paraná e Santa Catarina.

Cladonia multiformis, uma espécie conhecida para a África do Sul (Doidge 1950), Japão (Kashiwadani, 1975), Canadá, Estados Unidos da América (Brodo et al. 2001) e México (Ahti 2000). Mesmo sendo comum e abundante em diferentes localidades na Serra do Mar, tanto no Estado do Paraná quanto em Santa Catarina ainda não havia sido registrada para o continente sul americano, o que indica a carência de estudos em lugares de difícil acesso.

Para o Estado do Paraná são feitos quatro novos registros: Cladonia chlorophaea, C. grayi, C. polyscypha e C. pyxidata. Para o de Santa Catarina é relatada pela primeira vez a ocorrência de C. pyxidata.

Chave artificial para espécies de Cladonia do Supergrupo Cladonia com podécio cifoso e não verticilado da Serra do Mar do Sul do Brasil

1. Podécios fissurados longitudinalmente 4. C. multiformis

1. Podécios nunca fissurados longitudinalmente

2. Podécios com ápices regularmente cifosos, cifas iguais ou maiores que 2,3 mm diâm.

3. Superfície do podécio esorediada 8. C. pyxidata

3. Superfície do podécio sorediada

4. Superfície do podécio ecorticada

11. C. subsquamosa

4. Superfície do podécio corticada, ao menos em parte

5. Com ácido graiânico, UV + branco azulado a lilás 3. C. grayi

5. Sem ácido graiânico, UV 1. C. chlorophaea

2. Podécios com ápices subulados a cifosos, cifas iguais ou menores que 1,8 mm diâm.

6. Superfície do podécio esorediada

7. Superfície do podécio ecorticada

7. Superfície do podécio corticada

8. Superfície do podécio lisa a rugosa, filídios e esquizídos presentes

8. Superfície do podécio verrucosa, filídios e esquizídios ausentes

6. Superfície do podécio sorediada

9. Podécios com base melanótica

9. Podécios sem base melanótica

10. Sorédios dispostos em sorais 2. C. furfuracea

10. Sorédios dispostos sobre toda a superfície do podécio

5. C. ochracea 9. C. ramulosa 7. C. polyscypha 6. C. ochrochlora 10. C. subradiata

1. Cladonia chlorophaea (Flörke ex Sommerf.) Spreng. Syst. Veg. 4 (1): 273, 1827.

Figura 1

Talo primário: evanescente, composto por esquâmulas inconspícuas, recortadas, 0,4-0,9 $\mathrm{mm}$ compr.,
0,2-0,6 mm larg., sorédios e grânulos ausentes, margens crenadas, sem rizinas; superfície superior corticada, verde acinzentada, lisa, levemente lustrosa, pruína ausente; superfície inferior ecorticada, branca, aracnoide, sem venações; córtex 40-60 $\mu \mathrm{m}$ de espessura; medula 60-110 $\mu \mathrm{m}$ de espessura; picnídios 
ausentes. Talo secundário: 1,5-2,8 cm alt., 0,5-1,1 mm de espessura, cinza esbranquiçado, ápices regularmente cifosos, cifas com 2,3-3,3 mm diâm., simples a pouco ramificado, com até cinco ramificações na margem das cifas e com até três cifas sobrepostas, perfurações ausentes, sem base melanótica, porém geralmente amarronzada; superfície corticada até cerca da metade do podécio e algumas vezes dentro das cifas, sorédios granulosos abundantes na metade superior do podécio, esquâmulas esparsas, laciniadas, recortadas de até 1,1 $\mathrm{mm}$ compr., presentes principalmente na metade inferior do podécio; córtex (0-)17-30 $\mu \mathrm{m}$ de espessura; medula 25-100 $\mu \mathrm{m}$ de espessura; estereoma 70-200 $\mu \mathrm{m}$ de espessura, hialino, mal delimitado; canal central levemente estriado; discos himeniais na margem das cifas, marrons, imaturos; picnídios ausentes.

Química: Testes de coloração: K-, C-, KC-, UV-. CCD: ácido fumarprotocetrárico.

Cladonia chlorophaea é caracterizada pelos podécios regularmente cifosos e ecorticados, corticados somente na base, com sorédios granulosos na região superior e dentro das cifas, bem como pela produção de ácido fumarprotocetrárico como principal metabólito secundário (Galloway 1985, Swinscow \& Krog 1988, Burgaz \& Ahti 2009, Wang et al. 2011).

Cladonia pyxidata e C. subsquamosa são morfologicamente similares a $C$. chlorophaea e possuem a mesma química. Contudo, são diferenciadas pela superfície dos podécios, que é esorediada em $C$. pyxidata e totalmente ecorticada em C. subsquamosa.

Difere de Cladonia fimbriata (L.) Fr. pelos podécios parcialmente corticados, com cifas mais largas e pelos sorédios granulosos (McCune \& Geiser 1997, Wang et al. 2011). Além disso, Burgaz \& Ahti (2009) relataram que C. fimbriata é diferenciada pela coloração verde amarelada, ao passo que em C. chlorophaea é verde acinzentada.

Cladonia cryptochorophaea Asahina, C. grayi, C. merochorophaea Asahina e C. novochorophaea (Sipman) Brodo \& Ahti são espécies morfologicamente próximas a $C$. chlorophaea, mas que são diferenciadas por produzirem respectivamente ácidos criptoclorofeico, graiânico, meroclorofeico e sequicáico como compostos principais (Ahti 2000).

É uma espécie rara na área de estudo, onde foi encontrado somente um espécime desenvolvendo-se sobre briófitas, isolado de outras espécies de Cladoniaceae.
Distribuição: Cosmopolita (Ahti 2000, Burgaz \& Ahti 2009), registrada (em trabalhos do século XIX como C. pyxidata var. chlorophaea) para: Oceania, Ásia, África, (Vainio 1894), Europa (Crombie 1883), América do Norte (Vainio 1894), América Central (Ahti 2000), Antártida (Øvstedal \& Smith 2001) e América do Sul (Vainio 1894), na Argentina (Calvelo \& Liberatore 2002), Bolívia (Feuerer et al. 1998), Brasil, Chile (Vainio 1894), Colômbia, Equador (Ahti 2000), Guiana (Vainio 1894), Peru (Ahti 2000), Uruguai (Osorio 1972) e Venezuela (Lopez-Figueiras 1986). Brasil: RJ (Vainio 1894), RS (Fleig et al. 1995) e SP (Ahti 2000). Este é o primeiro registro para o Estado do Paraná.

Espécime examinado: BRASIL. Paraná: Guaratuba, Serra do Araçatuba, Morro dos Perdidos, 255'02"S e 48 57'35"W, 1.260 m.s.m., 15-IV-2011, A.M. Charnei et al. 58 (UPCB).

2. Cladonia furfuracea Vain., Acta Soc. Fauna Fl. Fenn. 10: 375, 1894.

Figura 2

Talo primário: persistente a evanescente, composto por esquâmulas laciniadas a lobadas, pouco recortadas, 0,4-2,6 $\mathrm{mm}$ compr., 0,3-0,9 mm larg., sorédios e grânulos ausentes, margens lisas, sem rizinas; superfície superior corticada, esverdeada a verde amarronzada, lisa, lustrosa, pruína ausente; superfície inferior ecorticada, branca, aracnoide, sem venações; córtex 20-45 $\mu \mathrm{m}$ de espessura; medula 30-80 $\mu \mathrm{m}$ de espessura; picnídios ausentes. Talo secundário: 0,9-4(-6) $\mathrm{cm}$ alt., 0,6-1,5 mm de espessura, cinza esbranquiçado a cinza amarronzado, marrom enegrecido em lugares expostos a luz solar, ápices subulados a principalmente estreito cifosos, cifas com até $1,8 \mathrm{~mm}$ diâm., simples a pouco ramificado, com até três ramificações nas margens das cifas, perfurações ausentes, sem base melanótica; superfície ecorticada, aracnoide a lisa, estereoma geralmente exposto e amarronzado, sorédios ausentes, grânulos escassos localizados principalmente na região apical, esquâmulas abundantes, laciniadas a isidioides, raramente recortadas com até 1,2 mm compr., na maioria das vezes curvadas para baixo; medula (0-)20-30(-50) $\mu \mathrm{m}$ de espessura; estereoma 120-200 $\mu \mathrm{m}$ de espessura, amarelado a amarronzado, bem delimitado; canal central liso; discos himeniais infrequentes, apicais, marrons, com até $1 \mathrm{~mm}$ diâm.; ascósporos ausentes; picnídios infrequentes, na margem das cifas, piriformes, marrom enegrecidos, 

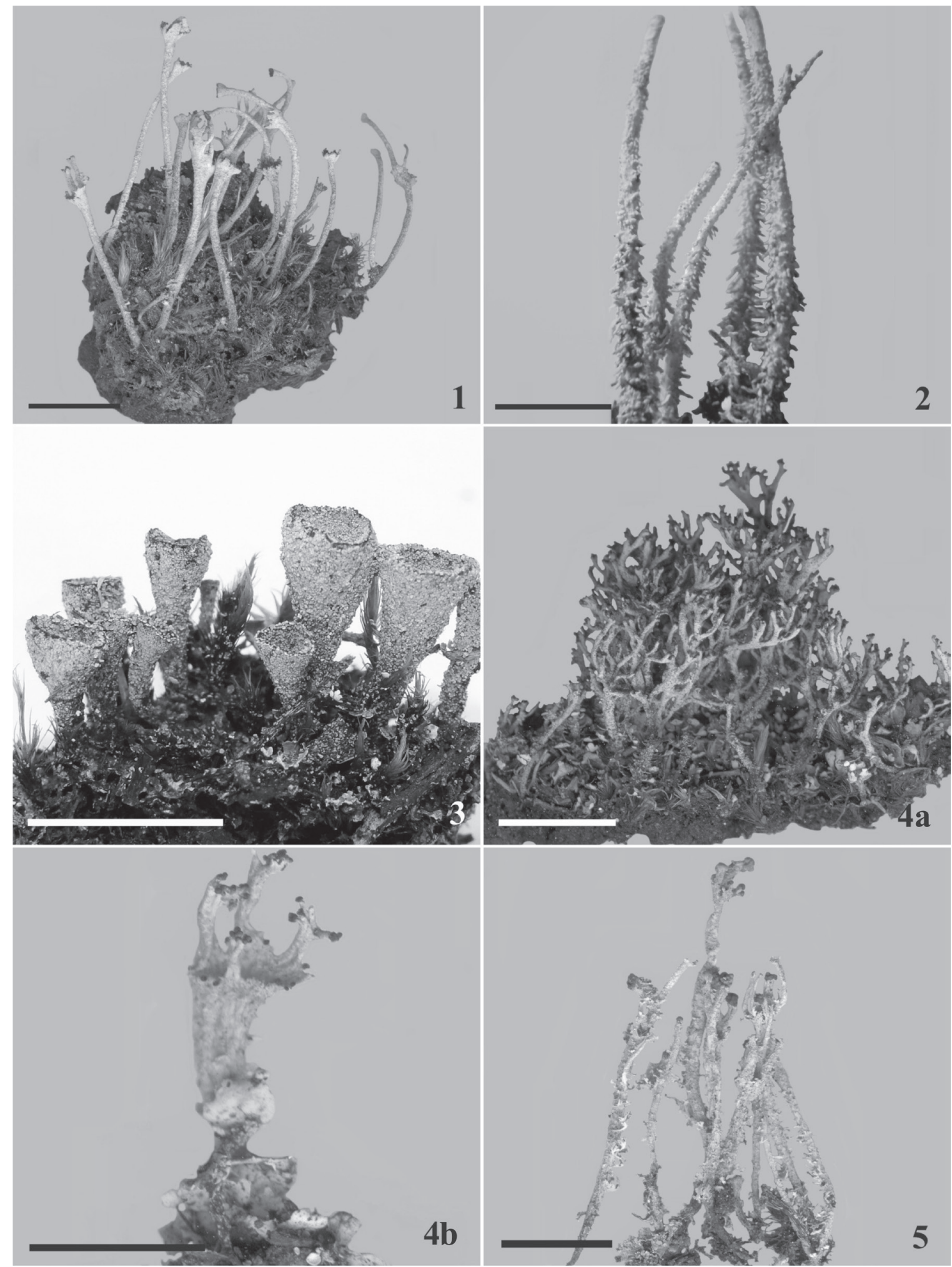

Figuras 1-5. 1. Cladonia chlorophaea (A.M. Charnei et al. 58). 2. C. furfuracea (A.M. Charnei et al. 303). 3. C. grayi (A.M. Charnei et al. 79). 4. C. multiformis. a. Podécios mais desenvolvidos, acifosos (A.M. Charnei et al. 28). b. Podécio menos desenvolvido, cifoso (A.M. Charnei et al. 145). 5. C. ochracea (E. Gumboski \& F. Beilke 2236). Barras de escala =1 cm.

Figures 1-5. 1. Cladonia chlorophaea (A.M. Charnei et al. 58). 2. C. furfuracea (A.M. Charnei et al. 303). 3. C. grayi (A.M. Charnei et al. 79). 4. C. multiformis. a. More developed podetia, ascyphose (A.M. Charnei et al. 28). b. Less developed podetia, scyphose (A.M. Charnei et al. 145). 5. C. ochracea (E. Gumboski \& F. Beilke 2236). Scale bars $=1 \mathrm{~cm}$. 
mucilagem hialina; conídios levemente curvados a falciformes, 6-7 × ca. $1 \mu \mathrm{m}$.

Química: Testes de coloração: K-, C-, KC-, UV-. CCD: ácido fumarprotocetrárico.

Esta espécie é caracterizada pelos podécios simples a pouco ramificados, com ápices subulados a estreito cifosos, superfície ecorticada, esorediada, com grânulos verruculosos e esquâmulas isidioides geralmente curvadas para baixo (Vainio 1894, Ahti 2000).

Assim como em Cladonia furfuracea, os podécios de C. furfuraceoides Ahti \& Sipman são ecorticados e com ápices subulados a estreito cifosos. No entanto, C. furfuraceoides difere pela base do podécio melanótica e pela ausência de esquâmulas isidioides (Stenroos et al. 2002).

Cladonia furfuracea é comumente encontrada na Serra do Mar, tanto no Estado do Paraná quanto em Santa Catarina. Desenvolve-se principalmente sobre solo e fina camada de sedimentos sobre rochas, mas também sobre musgos e restos de vegetais, geralmente entremeada com C. subradiata ou isolada de outras espécies de Cladonia.

Distribuição: De acordo com Stenroos et al. (2002), os registros para a Guiana (Sipman \& Aptroot 1992, Ahti 2000), Venezuela, Colômbia e para os estados brasileiros do AM e RR (Ahti 2000), referem-se a C. furfuraceoides. Assim, C. furfuracea é conhecida somente para o Brasil: BA (Ahti et al. 1993), ES (Ahti 2000), MG (Vainio 1894), PB (Ahti et al. 1993), PE, PR, RJ (Ahti 2000), RS (Fleig et al. 1995), SC (Ahti 2000), SP (Marcelli 1990) e SE (Ahti et al. 1993).

Espécimes examinados: BRASIL. Paraná: Campina Grande do Sul, Serra Virgem Maria, 1.400 m.s.m., 31-I-2004, C.G. Donha 1755 (UPCB). Morretes, Serra da Graciosa, Recanto Grota Funda, 17-VII-1999, G. Queiroz \& L. Klemann (UPCB). Quatro Barras, Serra da Baitaca, Morro Anhangava, 252 $3^{\prime} \mathrm{S}$ e 4900'W, 1.420 m.s.m., 14-VII-2011, A.M. Charnei et al. 248 (UPCB); Morro Mãe Catira, 1.100 m.s.m., 12-VIII-1989, R. Kummrov \& O.S. Ribas 3185 (MBM). Piraquara, Serra Marumbi, Morro do Canal, 8-V-2002, S. Eliasaro 2226 (UPCB); Morro do Bruninho, 1.230 m.s.m., 4-XI-2011, A.M. Charnei 471 (UPCB). Guaratuba, Serra do Araçatuba.

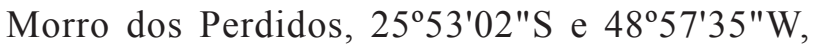
900 m.s.m., 31-VIII-2002, S. Eliasaro s. n. (UPCB); 1.260 m.s.m., 14-IV-2011, A.M. Charnei et al. 10 (UPCB). Santa Catarina: Garuva, Serra do Quiriri,
Monte Crista, 2604'56"S e 48 54'37"W, 970 m.s.m., 15-V-2010, E. Gumboski \& F. Beilke 1935 (UPCB). Joinville, Serra Queimada, 260' $14^{\prime \prime S ~ e ~} 49^{\circ} 02^{\prime} 46^{\prime \prime} \mathrm{W}$, 1.200 m.s.m., 30-IV-2010, Werner s. $n$ (UPCB). Santo Amaro da Imperatriz, Pico da Serra do Tabuleiro, $27^{\circ} 49^{\prime} \mathrm{S}$ e $48^{\circ} 53^{\prime} \mathrm{W}, 1.250$ m.s.m., 13-VIII-2011, A.M. Charnei et al. 303 (UPCB).

3. Cladonia grayi G. Merrill ex Sandstede, Clad. Exsicc., 1847. 1929.

Figura 3

Talo primário: persistente, composto por inconspícuas esquâmulas lobadas, 0,2-0,6 mm compr., 0,2-0,7 mm larg., geralmente formando crostas, sorédios e grânulos ausentes, margens crenadas, sem rizinas; superfície superior corticada, cinza esverdeada, lisa, opaca, pruína ausente; superfície inferior ecorticada, branca, aracnoide, sem venações; córtex 25-35 $\mu \mathrm{m}$ de espessura; medula 80-220 $\mu \mathrm{m}$ de espessura; picnídios ausentes. Talo secundário: 0,5-3(-5) cm alt., 0,8-2,5 mm de espessura, acinzentado, regularmente cifoso, cifas com até $0,5 \mathrm{~cm}$ diâm., margens inteiras a levemente denteadas, simples, eventualmente com até três ramificações a partir das margens das cifas, raramente do centro, com até três cifas sobrepostas, perfurações ausentes, base melanótica ausente, porém algumas vezes levemente amarronzada; superfície corticada, verrucosa, algumas vezes com áreas ecorticadas, sorédios principalmente ausentes, quando presentes localizados na região superior do podécio e dentro das cifas, grânulos abundantes, principalmente na região superior do podécio e dentro das cifas, filídios e esquizídios geralmente presentes, distribuídos por todo o podécio, esquâmulas recortadas, com até $0,7 \mathrm{~mm}$ compr., localizadas principalmente na metade inferior do podécio, algumas vezes nas margens das cifas; córtex 0-35 $\mu \mathrm{m}$ de espessura; medula 90-130 $\mu \mathrm{m}$ de espessura; estereoma 120-160 $\mu \mathrm{m}$ de espessura, hialino a amarelado, bem delimitado; canal central levemente sulcado; discos himeniais infrequentes, em pedicelos nas margens das cifas, marrons enegrecidos, com até 2,7 mm diâm.; ascósporos fusiformes, 9-13 $\times 3-4 \mu \mathrm{m}$; picnídios frequentes na margem das cifas, piriformes a ovoides, marrons, mucilagem hialina; conídios falciformes, 6-7 × ca. $1 \mu \mathrm{m}$.

Química: Testes de coloração: K-, C-, KC-, UV+ branco azulado. CCD: ácidos graiânico, 4-O-dimetilgraiânico e fumarprotocetrárico.

Cladonia grayi é a única espécie de Cladonia que ocorre no Brasil a produzir ácido graiânico, que emite 
uma fluorescência medular lilás sob luz UV (Galloway 1985, Ahti 2000) e, de acordo com Ahti (2000), esta fluorescência geralmente é caráter suficiente para a identificação da espécie. Nos espécimes estudados, tanto da área de estudo quanto no Estado do Rio Grande do Sul, foi observada uma leve fluorescência branca azulada, todavia, a presença de ácido graiânico foi confirmada por CCD.

Embora seja morfologicamente similar a Cladonia clorophaea, C. meroclorophaea, C. cryptochorophaea, C. novochorophaea e C. pyxidata, é facilmente diferenciada pela química medular.

Cladonia albonigra Brodo \& Ahti é uma espécie holártica (Brodo \& Ahti 1996, Holien 2005) que se assemelha a $C$. grayi pelos podécios regularmente cifosos e por frequentemente produzir ácido graiânico. No entanto, é diferenciada pela base dos podécios melanótica e pela frequente proliferação central das cifas (Brodo \& Ahti 1996).

Cladonia grayi desenvolve-se em diversos substratos, como musgos, solo, fina camada de sedimentos sobre rocha, córtex e restos vegetais em decomposição, tanto em locais sombreados como em áreas diretamente expostas à luz solar.

Distribuição: Cosmopolita (Galloway 1985). Na América do Sul: Argentina (Calvelo \& Liberatore 2002), Brasil (Fleig et al. 1995), Colômbia, Equador, Paraguai (Ahti 2000), Uruguai (Osorio 1972) e Venezuela (Lopez-Figueiras 1986). Brasil: MG, RJ (Ahti 2000), RS (Fleig et al. 1995), SC e SP (Ahti 2000). Este é o primeiro registro para o Estado do Paraná.

Espécimes examinados: BRASIL. ParanÁ: Campina Grande do Sul, Serra do Ibitiraquire, Morro do Getúlio, 2514'S e 48 50'W, 1.230 m.s.m., 6-VII-2011, A.M. Charnei et al. 138, 148, 154 (UPCB). Piraquara, Serra Marumbi, Morro do Canal, 29-V-2002, S. Eliasaro 2227, 2356, 2358 (UPCB). Guaratuba, Serra do Araçatuba, Morro dos Perdidos, 2553'02"S e 48 57'35"W, 900 m.s.m., 31-VIII-2002, S. Eliasaro 2431 (UPCB); ibid. 1.260 m.s.m., 15-IV-2011, A.M. Charnei et al. 1, 14, 48, 79, 82 (UPCB). SANTA Catarina: Garuva, Serra do Quiriri, 2603'36"S e 48 56'35"W, 1.164 m.s.m., 7-V-2011, A.M. Charnei et al. 87, 93 (UPCB); Monte Crista, 260.'56"S e 4854'37"W, 967 m.s.m., 7-V-2011, A.M. Charnei et al. 103 (UPCB). Joinville, Serra Dona Francisca, Castelo dos Bugres, 26² $13^{\prime} \mathrm{S}$ e $49^{\circ} 03^{\prime} \mathrm{W}, 998$ m.s.m., 7-I-2011, E. Gumboski \& F. Beilke 2244 (UPCB). Santo Amaro da Imperatriz, Pico da Serra do Tabuleiro, $27^{\circ} 49^{\prime} \mathrm{S}$ e 48 $53^{\prime}$ W, 1.250 m.s.m., 13-VIII-2011, A.M. Charnei et al. 334 (UPCB).

Espécimes adicionais examinados: BRASIL. Rio de Janeiro: Porto Alegre, Reserva Ecológica Lami, 10 m.s.m., 19-IX-1981, M. Fleig 1406 (ICN). Cambará do Sul, Itaimbezinho, 900-m.s.m., 30-IV-1989, M. Fleig. 3553 (ICN).

4. Cladonia multiformis G. Merr., Bryologist 12:1. 1909.

Figuras 4a-b

Talo primário: geralmente persistente a ocasionalmente evanescente, composto por esquâmulas lobadas, com 1,3-5,5 mm compr., 1-4 mm larg., sorédios e grânulos ausentes, margens lisas, sem rizinas; superfície superior corticada, verde, verde oliva a verde amarronzada, lisa a raramente verrucosa, levemente lustrosa, pruína ausente; superfície inferior ecorticada, branca, aracnoide, sem venações; córtex 50-160 $\mu \mathrm{m}$ de espessura; medula 120-300 $\mu \mathrm{m}$ de espessura; picnídios laminais, escassos, negros, globosos, mucilagem hialina; conídios levemente curvados a falciformes, $(5-) 6-8 \times$ ca. $1 \mu \mathrm{m}$. Talo secundário: 0,3-2,8 cm alt., 0,7-1,8 $\mathrm{mm}$ de espessura, cinza esverdeado a cinza amarronzado, simples em talos pouco desenvolvidos e ramificado em talos desenvolvidos, ramificações a partir da margem das cifas, cifas com até $5 \mathrm{~mm}$ diâm., perfuradas, melhor observadas em talos pouco desenvolvidos e sem ramificações, sem base melanótica, podécio fissurado longitudinalmente, fissuras ausentes a escassas em podécios pouco desenvolvidos; superfície principalmente corticada, com áreas ecorticadas em talos pouco desenvolvidos, lisa a verrucosa, sorédios e grânulos ausentes, esquâmulas lobadas de até 1,7 mm compr., frequentemente localizadas na base do podécio; córtex (0-)30-40 $\mu \mathrm{m}$ de espessura; medula 50-140 $\mu \mathrm{m}$ de espessura; estereoma 70-140 $\mu \mathrm{m}$ de espessura, hialino, mal delimitado; canal central levemente estriado; discos himeniais abundantes, apicais, marrons, 0,2-1 mm diâm.; ascósporos elipsoides, $8-11 \times$ ca. $4 \mu \mathrm{m}$; picnídios na margem das cifas, frequentes em talos pouco desenvolvidos, ausentes a escassos em talos desenvolvidos, com a mesma morfologia dos encontrados nas esquâmulas primárias.

Química: K- ou K+ amarelo sujo, C-, KC-, UV-. CCD: ácido fumarprotocetrárico. 
Brodo et al (2001) destacaram que Cladonia multiformis, como o próprio nome indica, possui ampla variação morfológica. Os podécios variam de simples e cifosos quando pouco desenvolvidos e estéreis a muito ramificados e acifosos quando férteis (Merril 1909, Ahti \& Hammer 2002). No entanto, pode ser caracterizada pelo podécio fissurado (Howard 1950), com cifas perfuradas, melhor observadas em podécios pouco desenvolvidos, superfície esorediada, bem como pela produção de ácido fumarprotocetrárico (Brodo et al. 2001, Ahti \& Hammer 2002).

De acordo com Ahti \& Hammer (2002), na maioria das vezes somente os podécios férteis são encontrados, sendo extremamente similares aos de Cladonia furcata (Hudson) Schrader. Neste caso, são diferenciadas pelo tamanho, não ultrapassando $4,5 \mathrm{~cm}$ em C. multiformis (Brodo et al. 2001), enquanto que em C. furcata podem atingir até $23 \mathrm{~cm}$ (Ahti 2000). Aliado a estas diferenças, notamos que nos exemplares de C. multiformis da área de estudo os discos himeniais são maiores, com 0,2-1 mm diâm., ao passo que em C. furcata os discos himeniais, além de serem observados em menor quantidade, não ultrapassam 0,2 mm diâm.

Esta espécie é comum na área de estudo, geralmente formando densos aglomerados de podécios que se desenvolvem na maioria das vezes isoladamente de outras espécies de Cladoniaceae, sobre solo, fina camada de sedimentos sobre rochas e sobre musgos.

Distribuição: América do Norte (Krog 1968), Japão (Kashiwadani 1975) e África (Doidge 1950, como C. multiformis f. subascypha). Este é o primeiro registro para a América do Sul.

Espécimes examinados selecionados: BRASIL. PARAnÁ: Campina Grande do Sul, Serra do Ibitiraquire, pico Paraná, $25^{\circ} 15^{\prime} \mathrm{S}$ e $48^{\circ} 48^{\prime} \mathrm{W}, 1.880$ m.s.m., 6-VII-2011, A.M. Charnei et al. 233 (UPCB); Morro do

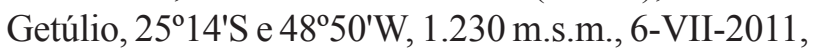
A.M. Charnei et al. 142, 145 (UPCB). Piraquara, Serra do Marumbi, Morro do Canal, 29-V-2002, S. Eliasaro 2357 (UPCB). Quatro Barras, Serra da Baitaca, Morro Anhangava, $25^{\circ} 23^{\prime} \mathrm{S}$ e $49^{\circ} 00^{\prime} \mathrm{W}, 1.420$ m.s.m., 14-VII-2011, A.M. Charnei et al. 235, 256, 281, 285 (UPCB). Guaratuba, Serra do Araçatuba, Morro dos Perdidos, $25^{\circ} 53^{\prime} 02^{\prime \prime S}$ e $48^{\circ} 57^{\prime} 35^{\prime \prime} \mathrm{W}, 1.260$ m.s.m., 15-IV-2011, A.M. Charnei et al. 11, 26, 28, 54, 61, 83 (UPCB). SANTA CATARINA: Garuva, Serra

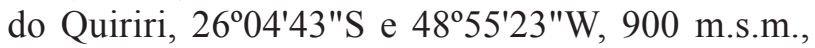
7-V-2011, A.M. Charnei et al. 98 (UPCB). Campo

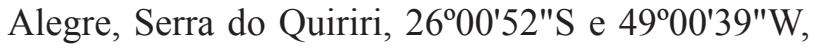

900 m.s.m., 26-XII-2011, E. Gumboski \& F. Beilke 3237,3238 (UPCB). Joinville, Serra Dona Francisca, Castelo dos Bugres, 2523'16"S e $49^{\circ} 00^{\prime} 08^{\prime \prime} \mathrm{W}$, 998 m.s.m., 7-I-2011, E. Gumboski \& F. Beilke 2218, 2230, 2231 (UPCB), ibid. 12-VIII-2011, A.M. Charnei et al. 415, 421 (UPCB).

5. Cladonia ochracea L. Scriba, in Sandstede, Clad. Exsicc. 1006, 1923.

Figura 5

Talo primário: persistente a evanescente, composto por esquâmulas laciniadas, recortadas, 0,7-2,1 mm compr., 0,4-1,2 mm larg., sorédios e grânulos ausentes, margens crenadas, sem rizinas; superfície superior corticada, cinza esverdeada a cinza amarronzada, lisa, levemente lustrosa, pruína ausente; superfície inferior ecorticada, branca a bege, aracnoide, sem venações; córtex 15-35 $\mu \mathrm{m}$ de espessura; medula 30-110 $\mu \mathrm{m}$ de espessura; picnídios laminais, pouco frequentes, negros, piriformes, mucilagem hialina; conídios falciformes, $6-8 \times$ ca. $1 \mu \mathrm{m}$. Talo secundário: 0,9-3,4 cm alt., 0,5-1,4 $\mathrm{mm}$ de espessura, cinza esbranquiçado a cinza amarronzado, ápices subulados a principalmente estreito cifosos, cifas com até $1,5 \mathrm{~mm}$ diâm., simples a pouco ramificado, ramificações na metade superior do podécio ou nas margens das cifas, perfurações ausentes, sem base melanótica; superfície corticada, geralmente areolada até cerca a metade do podécio, próximo e dentro das cifas, escabrosa, sorédios ausentes, grânulos finos que podem ser confundidos com sorédios localizadas principalmente na região superior do podécio, escassos, esquâmulas laciniadas, recortadas ou não, com até $0,9 \mathrm{~mm}$ compr., filídios e esquizídios abundantes, distribuídos por todo podécio; córtex (0-)10-30 $\mu \mathrm{m}$ de espessura; medula 35-70 $\mu \mathrm{m}$ de espessura; estereoma 40-120 $\mu \mathrm{m}$ de espessura, mal delimitado, hialino; canal central papilado e levemente sulcado; discos himeniais frequentes, apicais, marrons, com até 1,8 mm diâm.; ascósporos fusiformes $11-13 \times 3-5 \mu \mathrm{m}$; picnídios pouco frequentes, na margens das cifas, com a mesma morfologia dos encontrados nas esquâmulas primárias.

Química: Testes de coloração: K- ou K+ amarelo, C-, KC-, UV-. CCD: ácido fumarprotocetrárico, eventualmente associado aos ácidos estíctico, criptostíctico e connorestíctico (a associação de ácido fumarprotocetrárico com estes compostos é relatada pela primeira vez para esta espécie).

Cladonia ochracea é caracterizada pelos podécios cifosos, simples a pouco ramificados com superfície 
corticada na base, escabrosa com esquâmulas, filídios e esquizídios abundantes (Fleig et al. 1995, Ahti 2000).

Cladonia ramulosa é a espécie da área de estudo que mais se assemelha a C. ochracea. Contudo, em C. ramulosa a superfície é quase totalmente corticada, rugosa a verrucosa e sem filídios e/ou esquizídios.

De acordo com Ahti (2000), C. ochracea ocorre desde o nível do mar até 1.900 m.s.m. Na área de estudo desenvolve-se principalmente em áreas mais expostas à luz solar e isolada de outras espécies de Cladonia.

Distribuição: América do Sul: Argentina (Ahti 2000), Brasil (Osorio \& Fleig 1991), Paraguai e Uruguai (Ahti 2000). Brasil: ES, MG, MS (Ahti 2000), PR (Gumboski \& Eliasaro 2012), RJ (Ahti 2000), RS (Osorio \& Fleig 1991), SC e SP (Ahti 2000).

Espécimes examinados: BRASIL. PARANÁ: Campina Grande do Sul, Serra do Ibitiraquire, Morro do

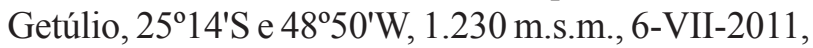
A.M. Charnei et al. 150 (UPCB). Quatro Barras, Serra da Baitaca, Morro Anhangava, $25^{\circ} 23^{\prime} \mathrm{S}$ e $49^{\circ} 00^{\prime} \mathrm{W}$, 1.420 m.s.m., 14-VII-2011, A.M. Charnei et al. 238 (UPCB). Guaratuba, Serra do Araçatuba, Morro dos Perdidos, $25^{\circ} 53^{\prime} \mathrm{S}$ e $48^{\circ} 57^{\prime} \mathrm{W}, 1.260$ m.s.m., 15-IV-2011, A.M. Charnei et al. 05 (UPCB). SANTA Catarina: Garuva, Serra do Quiriri, Monte Crista, 2604'56"S e 4854'37"W, 970 m.s.m., 15-V-2010, E. Gumboski \& F. Beilke 1971, 1982 (UPCB). Joinville, Serra Dona Francisca, Castelo dos Bugres, $26^{\circ} 13^{\prime} 41^{\prime \prime S}$ e $49^{\circ} 03^{\prime} 33^{\prime \prime} \mathrm{W}, 998$ m.s.m., 7-I-2011, E. Gumboski \& F. Beilke 2233, 2236, 2238 (UPCB).

6. Cladonia ochrochlora Flörke, De Cladoniis, Difficillimo lichenun genero, Commentatio Nova 75, 1828.

Figura 6

Talo primário: geralmente persistente a raramente evanescente, composto por esquâmulas laciniadas, raramente lobadas, frequentemente recortadas, 0,5-5 mm compr., 0,6-4 mm larg., ascendentes, sorédios principalmente ausentes, quando presentes são escassos e distribuem-se nas margens e na superfície inferior, grânulos ausentes, margens crenadas, sem rizinas; superfície superior corticada, esverdeada, lisa, levemente lustrosa, pruína ausente; superfície inferior ecorticada, branca, algumas vezes tornando-se amarronzada próximo a base, aracnoide, sem venações; córtex 40-60 $\mu \mathrm{m}$ de espessura; medula 40-140 $\mu \mathrm{m}$ de espessura; picnídios ausentes.
Talo secundário: 0,6-2 $\mathrm{cm}$ alt., 0,5-1,9 $\mathrm{mm}$ de espessura, cinza esbranquiçado a cinza esverdeado, frequentemente simples a raramente ramificado, com até três ramificações na metade superior, ápices subulados a estreito cifosos, cifas com até $1,7 \mathrm{~mm}$ diâm., sem base melanótica, porém algumas vezes tornando-se amarela amarronzada, sem perfurações; superfície do podécio corticada, principalmente na metade inferior e próximo as cifas, sorédios farinosos a granulosos, principalmente produzidos em sorais, raramente distribuídos por todo podécio, sorais principalmente na metade superior do podécio, grânulos ausentes, esquâmulas esparsas a ausentes, localizadas principalmente na metade inferior do podécio; córtex (0-)20-50 $\mu \mathrm{m}$ de espessura; medula 50-110 $\mu \mathrm{m}$ de espessura; estereoma 50-90 $\mu \mathrm{m}$ de espessura, mal delimitado, hialino; canal central papilado; discos himeniais apicais, frequentes, marrons, 0,5-1 mm diâm.; ascósporos ausentes; picnídios infrequentes, dispostos na margem das cifas, globosos, marrom enegrecidos, mucilagem hialina; conídios levemente curvados a falciformes, 6-9 $\times$ ca. $1 \mu \mathrm{m}$.

Química: Testes de coloração: K-, C-, KC-, UV-. CCD: ácido fumarprotocetrárico.

Esta espécie é caracterizada pelos podécios simples com ápices subulados a estreito cifosos, superfície corticada na base do podécio e no interior das cifas, com sorédios farinosos a raramente granulosos, principalmente em sorais (Ahti 2000).

De todas as espécies do Supergrupo Cladonia encontradas na área de estudo, esta é a única que possui sorédios produzidos em sorais, assim podendo ser facilmente identificada.

Diferencia-se de C. coniocraea (Flörke) Spreng. pelos podécios com cifas corticadas e pela formação de sorais, características ausentes em C. coniocraea (Ahti 2000).

Embora Cladonia rei Schaer. seja morfologicamente semelhante, é facilmente diferenciada pela composição química, uma vez que produz ácido homosequicáico, composto ausente em C. ochrochlora (Galloway 1985, Brodo et al. 2001).

Assim como relatado por Brodo \& Ahti (1996), a maioria dos espécimes de $C$. ochrochlora analisados desenvolve-se sobre lenho em decomposição, sendo que somente um espécime é terrícola.

Distribuição: Cosmopolita: Oceania, Ásia (Vainio 1894), Europa (Crombie 1883), África, América do 

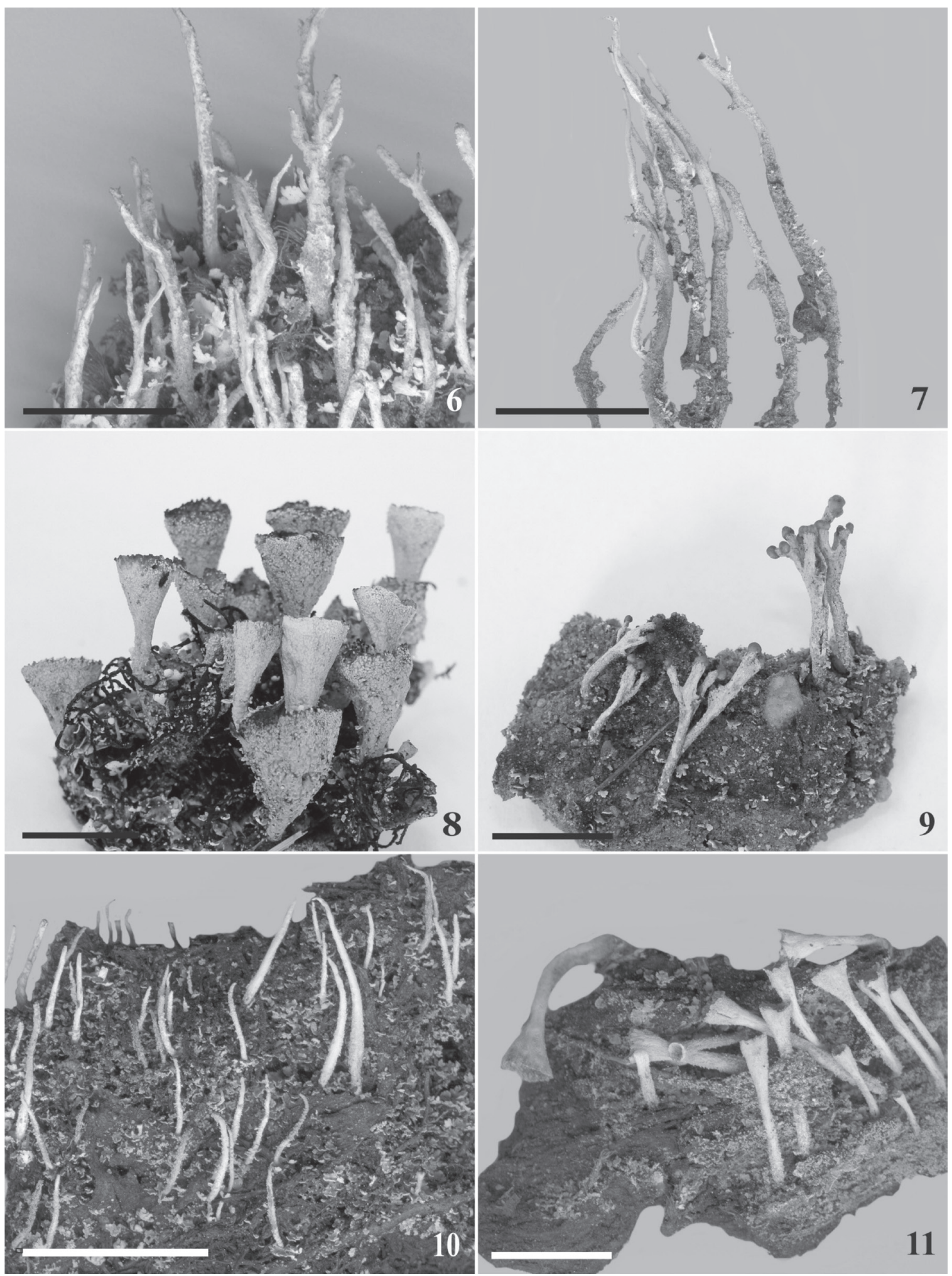

Figuras 6-11. 6. Cladonia ochrochlora (A.M. Charnei et al. 151). 7. C. polyscypha (A.M. Charnei et al. 408). 8. C. pyxidata (F.B. Matos s.n.). 9. C. ramulosa (A.M. Charnei et al. 137). 10. C. subradiata (F. Beilke et al. 33). 11. C. subsquamosa (A.M. Charnei et al. 440). Barras de escala $=1 \mathrm{~cm}$.

Figures 6-11. 6. Cladonia ochrochlora (A.M. Charnei et al. 151). 7. C. polyscypha (A.M. Charnei et al. 408). 8. C. pyxidata (F.B. Matos s.n.). 9. C. ramulosa (A.M. Charnei et al. 137). 10. C. subradiata (F. Beilke et al. 33). 11. C. subsquamosa (A.M. Charnei et al. 440). Scale bars $=1 \mathrm{~cm}$. 
Norte (Vainio 1894) e América do Sul (Muller 1881), na Argentina (Calvelo \& Liberatore 2002), Bolívia (Ahti 2000), Brasil (Muller 1981), Chile, Colômbia (Ahti 2000), Cuba, Equador, Peru, (Ahti 2000), Venezuela (Lopez-Figueiras 1986) e Uruguai (Osorio 1972). Brasil: MG, RJ (Ahti 2000), RS (Fleig et al. 1995), SC (Muller 1981) e SP (Ahti 2000).

Espécimes examinados: BRASIL. PARANÁ: Campina Grande do Sul, Serra do Ibitiraquire, Morro Caratuva, $25^{\circ} 24^{\prime} \mathrm{S}$ e $48^{\circ} 49^{\prime} \mathrm{W}, 1.850$ m.s.m., 6-VII-2011, A.M. Charnei et al. 168, 169 (UPCB); Morro do Getúlio, $25^{\circ} 14^{\prime} \mathrm{S}$ e $48^{\circ} 50^{\prime} \mathrm{W}, 1.230$ m.s.m., 6-VII-2011, A.M. Charnei et al. 151 (UPCB). SANTA CATARINA: Joinville, Serra Queimada, 260 $07^{\prime} 14^{\prime \prime S}$ e $49^{\circ} 02^{\prime} 46^{\prime \prime} \mathrm{W}$, 1.240 m.s.m., 4-IX-2011, A.M. Charnei \& F. Beilke 442 (UPCB).

7. Cladonia polyscypha Ahti \& Xavier Filho, in Ahti et al., Trop. Bryol. 7: 61, 1993.

Figura 7

Talo primário: persistente a evanescente, composto por esquâmulas lobadas a laciniadas, geralmente recortadas, 0,9-2,5 $\mathrm{mm}$ compr., 0,4-2 mm larg., sorédios ausentes, grânulos raramente presentes nas margens, escassos, margens crenadas, sem rizinas; superfície superior corticada, esverdeada, lisa, levemente lustrosa, pruína ausente; superfície inferior ecorticada, branca, aracnoide, sem venações; córtex 30-60 $\mu \mathrm{m}$ de espessura; medula 40-120 $\mu \mathrm{m}$ de espessura; picnídios ausentes. Talo secundário: 1,5-3,4 cm alt., 0,4-2,3 $\mathrm{mm}$ de espessura, cinza esbranquiçado, pouco ramificado, ápices subulados a estreito cifosos, cifas com até $1,5 \mathrm{~mm}$ diâm. e três ramificações na margem, perfurações ausentes, base melanótica geralmente bem evidente; superfície completamente ecorticada a corticada somente na base, sorédios farinosos a granulosos dispersos por todo o podécio, grânulos ausentes, esquâmulas com até $1 \mathrm{~mm}$ compr., dispersas principalmente na base; córtex (0-)10-35 $\mu \mathrm{m}$ de espessura; medula 30-110 $\mu \mathrm{m}$ de espessura; estereoma 130-200 $\mu \mathrm{m}$ de espessura, mal delimitado, melanótico nas partes basais e hialino na região superior do podécio; canal central sulcado e levemente papilado; discos himeniais e picnídios ausentes.

Química: Testes de coloração: K-, C-, KC-, UV-. CCD: ácido fumarprotocetrárico e traços de ácido fisodálico.

Os podécios cifosos, corticados somente na base, sorediados, com base melanótica e a produção de ácido fumarprotocetrárico (Ahti et al. 1993, Ahti 2000) caracterizam C. polyscypha.

Cladonia subradiata é a espécie que mais se assemelha a $C$. polyscypha, uma vez que ambas possuem podécios com ápices subulados a estreito cifosos com superfície ecorticada e sorediada, além de produzirem ácido fumarprotocetrárico. Todavia, C. subradiata não possui base melanótica.

Cladonia furfuraceoides também é semelhante a C. polyscypha pela base distintamente melanótica, ápices estreito cifosos, superfície ecorticada e por produzir ácido fumarprotocetrárico (Stenroos et al. 2002). No entanto, a superfície de C. furfuraceoides é esorediada.

Cladonia polyscypha ocorre desde o nível do mar até 1.100 m.s.m., principalmente em solos arenosos (Ahti 2000). É uma espécie pouco comum na área de estudo, onde foi encontrada desenvolvendo-se sobre solo e fina camada de sedimentos sobre rocha.

Distribuição: América do Sul: Brasil (Ahti et al. 1993), Guiana, Guiana Francesa e Venezuela (Ahti 2000). Brasil: AM (Ahti 2000), PB (Ahti et al. 1993), PE, RJ (Ahti 2000), SC (Gumboski \& Eliasaro 2012), SP (Ahti 2000) e SE (Ahti et al. 1993). Este é o primeiro registro para o Estado do Paraná.

Espécimes examinados: BRASIL. PARANÁ: Morretes, Serra da Graciosa, 17-VII-1999, F. L. Brock et al. s. $n$. (UPCB). SANTA CATARINA: Joinville, Serra Dona Francisca, Castelo dos Bugres, $26^{\circ} 13^{\prime} \mathrm{S}$ e $49^{\circ} 03^{\prime} \mathrm{W}$, 998 m.s.m., 7-I-2011, E. Gumboski \& F. Beilke 2269 (UPCB), ibid, 12-VIII-2011, A.M. Charnei et al. 408 (UPCB).

8. Cladonia pyxidata (L.) Hoff. Deutschl. Fl. 2: 121, 1796.

Figura 8

Talo primário: persistente, composto por esquâmulas lobadas, algumas vezes recortadas, 0,5-3 mm compr., 0,7-3 mm larg., ascendentes, sorédios e grânulos ausentes, margens lisas, sem rizinas; superfície superior corticada, verde acinzentada a verde amarronzada, lisa a levemente verrucosa, lustrosa, sem pruína; superfície inferior ecorticada, branca, aracnoide, sem venações; córtex 50-150 $\mu \mathrm{m}$ de espessura; medula 100-230 $\mu \mathrm{m}$ de espessura; picnídios ausentes. Talo secundário: 0,5-1,8 cm alt., 0,9-3 mm de espessura, cinza esverdeado a cinza esbranquiçado, regularmente cifoso, cifas com até $0,6 \mathrm{~cm}$ diâm., com até três ramificações principalmente na margem 
a ocasionalmente do centro das cifas, perfurações ausentes, sem base melanótica; superfície verrucosa, completamente corticada na base, areolada e com grandes áreas ecorticadas nas regiões superiores do podécio, totalmente ecorticada dentro das cifas, sorédios ausentes, grânulos abundantes nas regiões superiores e dentro das cifas, esquâmulas lobadas com até $0,8 \mathrm{~mm}$ compr., localizadas principalmente na base do podécio e na margem das cifas, grânulos e esquâmulas aplanadas localizadas dentro das cifas; córtex 0-30 $\mu \mathrm{m}$ de espessura; medula 50-80 $\mu \mathrm{m}$ de espessura; estereoma 130-400 $\mu \mathrm{m}$ de espessura, hialino, mal delimitado; canal central liso a levemente sulcado; discos himeniais frequentes, na margem das cifas, marrons, com até $0,5 \mathrm{~mm}$ diâm.; ascósporos elipsoides, $8-13 \times 3-4 \mu \mathrm{m}$; picnídios frequentes, na margem das cifas, ovoides a piriformes, marrons, mucilagem hialina; conídios falciformes, 7-9 $\times$ ca. $1 \mu \mathrm{m}$.

Química: Testes de coloração: K-, C-, KC-, UV-. CCD: ácido fumarprotocetrárico e traços de ácidos confumarprotocetrárico e protocetrárico.

Cladonia pyxidata é caracterizada pelos podécios que se alargam de maneira gradual para a formação das cifas, as quais são recobertas, na parte superior e especialmente internamente, por microesquâmulas aplanadas (Ahti \& Hammer 2002, Burgaz \& Ahti 2009).

Cladonia pocillum (Ach.) Grognot é muito semelhante a $C$. pyxidata por possuir esquâmulas primárias persistentes e podécios constantemente cifosos com superfície corticada na base e ecorticada nas regiões superiores (Ahti 2000, Brodo et al. 2001, Burgaz \& Ahti 2009). Embora, de acordo com Ahti (2000), a delimitação destas duas espécies necessite de mais estudos, podem ser diferenciadas pelas características das esquâmulas primárias, sendo que em C. pocillum mais espessas, fundidas e de coloração marrom (Ahti \& Hammer 2002).

Cladonia chlorophaea é a espécie da área de estudo mais próxima morfológica e quimicamente a C. pyxidata (ver comentários em C. chlorophaea).

De acordo com Ahti \& Hammer (2002), Cladonia pyxidata raramente ocorre sobre madeira em decomposição. Todavia, $25 \%$ dos espécimes da área de estudo foram encontrados desenvolvendo-se sobre este substrato e os demais sobre solo ou fina camada de sedimentos sobre rochas.

Distribuição: Cosmopolita (Vainio 1894). Na América do Sul: Argentina (Calvelo \& Liberatore 2002), Brasil
(Ahti 2000), Venezuela (Lopez-Figueiras 1986) e Uruguai (Osorio 1972). Brasil: BA, MG, ES, RJ e RS (Ahti 2000). Este é o primeiro registro para os Estados do Paraná e Santa Catarina.

Espécimes examinados: BRASIL. PARANÁ: Quatro Barras, Serra da Baitaca, Morro Anhangava, 2523'16"S e 4900'08"W, 1.200 m.s.m., 14-VII-2011, A.M. Charnei et al. 236, 282 (UPCB). Piraquara, Serra Marumbi, Mananciais da Serra, 900 m.s.m., 11-IX-2005, F. B. Matos s. n. (UPCB). Guaratuba, Serra do Araçatuba, Morro dos Perdidos, 255'02"S e 48 57'35"W, 1.260 m.s.m., 15-IV-2011, A.M. Charnei et al. 44 (UPCB). Santa Catarina: Campo

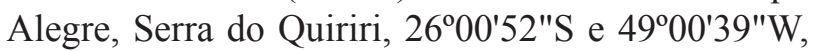
900 m.s.m., 26-XII-2011, E. Gumboski \& F. Beilke 3228, 3255 (UPCB). Joinville, Serra Queimada, 2607'14"S e 4902'46"W, 1.240 m.s.m., 4-IX-2011, A.M. Charnei \& F. Beilke 430, 439 (UPCB).

9. Cladonia ramulosa (With.) J. R. Laundon, Lichenologist 16: 225, 1984.

\section{Figura 9}

Talo primário: persistente, composto por esquâmulas lobadas a laciniadas, recortadas, 0,6-2 $\mathrm{mm}$ compr., 0,4-1,5 mm larg., imbricadas, ascendentes, sorédios e grânulos ausentes, margens crenadas, sem rizinas; superfície superior corticada, cinza esverdeada, lisa, pouco lustrosa, pruína ausente; superfície inferior ecorticada, branca, aracnoide, sem venações; córtex 15-40 $\mu \mathrm{m}$ de espessura; medula 30-150 $\mu \mathrm{m}$ de espessura; picnídios ausentes. Talo secundário: 0,7-1,6 cm alt., 0,5-1,2 mm de espessura, cinza esverdeado a cinza esbranquiçado, simples a pouco ramificado, com até sete ramificações a partir da margem das cifas, ápices subulados a cifosos, cifas com até 1,5 mm diâm., nem sempre evidentes devido às ramificações, perfurações ausentes, sem base melanótica; superfície quase completamente corticada, rugosa a verrucosa, sorédios ausentes, grânulos principalmente ausentes, quando presentes em podécios pouco desenvolvidos, escassos, esquâmulas lobadas a laciniadas, geralmente recortadas, com até 1,2 mm compr., localizadas principalmente na base do podécio; córtex (0-)5-15 $\mu \mathrm{m}$ de espessura; medula 30-80 $\mu \mathrm{m}$ de espessura; estereoma 60-100 $\mu \mathrm{m}$ de espessura, hialino, mal delimitado; canal central estriado; discos himeniais frequentes, apicais, marrons a marrom enegrecidos, 0,5-2 mm diâm.; ascósporos fusiformes, $14-16 \times$ ca. $3 \mu \mathrm{m}$; picnídios na margem das cifas, frequentes, globosos, marrom enegrecidos, 
mucilagem hialina; conídios levemente curvados, $6-7(-8) \times$ ca. $1 \mu \mathrm{m}$.

Química: Testes de coloração: K-, C-, KC-, UV-. CCD: ácido fumarprotocetrárico.

Cladonia ramulosa é bastante variável morfologicamente (Burgaz \& Ahti 2009), sendo caracterizada pelos podécios principalmente simples, cifosos, corticados, com superfície rugosa a verrucosa, granulosa e esquamulosa, sem sorédios (Ahti 2000, Burgaz \& Ahti 2009).

Ahti (2000) e Gumboski \& Eliasaro (2012) descreveram picnídios nas esquâmulas primárias, característica não observada nos materiais analisados. Por outro lado, todas as demais características analisadas conferem com as descrições destes autores.

Cladonia ochracea é a espécie da área de estudo que mais se assemelha a C. ramulosa (ver comentários em C. ochracea).

Cladonia pseudopityrea Vain. difere de C. ramulosa pelos podécios mais delicados, com córtex descontínuo e com picnídios distribuídos principalmente nas esquâmulas primárias (Burgaz \& Ahti 2009). Aliado as diferenças morfológicas, não há registros de $C$. pseudopityrea para a região Neotropical.

Cladonia rei é semelhante a C. ramulosa pelos podécios cifosos, com proliferações nas margens das cifas, as quais geralmente produzem discos himeniais marrons em seus ápices (Brodo et al. 2001). Contudo, possui sorédios farinosos na metade superior do podécio (Brodo et al. 2001, Wang et al. 2011) ausentes em C. ramulosa. Também diferem quimicamente, C. rei produz ácido homosequicáico algumas vezes associado ao ácido fumarprotocetrárico (Brodo et al. 2001) enquanto que C. ramulosa produz somente ácido fumarprotocetrárico.

Cladonia ramulosa ocorre desde o nível do mar até cerca de 2.000 m.s.m. (Ahti 2000). Na Serra do Mar no Sul do Brasil foi encontrada somente no Morro do Getúlio, onde se desenvolvia sobre solo em área exposta a luz solar, juntamente com $C$. multiformis e Cladia aggregata (Sw.) Nyl.

Distribuição: Cosmopolita (Vainio 1894, como C. pityrea). América do Sul: Argentina (Ferraro \& Ahti 1987), Brasil (Osorio \& Fleig 1988), Colômbia, Paraguai (Ahti 2000), Peru (Vainio 1894, como C. pityrea), Uruguai e Venezuela (Ahti 2000). Brasil: AM, MG, PA (Ahti 2000), PE (Ahti et al. 1993), PR, RJ, RR (Ahti 2000), RS (Osorio \& Fleig 1988), SC e SP (Ahti 2000).
Espécimes examinados: BRASIL. PARANÁ: Campina Grande do Sul, Serra do Ibitiraquire, Morro do Getúlio, 25ำ14'S e 48 50'W, 1.230 m.s.m., 6-VII-2011, A.M. Charnei et al. 137, 139 (UPCB).

10. Cladonia subradiata (Vain.) Sands., Abh. Naturwiss. Vereine Bremen 25: 230, 1922. Figura 10

Talo primário: geralmente evanescente a ocasionalmente persistente, composto por esquâmulas lobadas a laciniadas, recortadas, 0,4-1,7 mm compr., 0,6-1,4 mm larg., sorédios ausentes, grânulos incomuns localizados na margem ou na superfície inferior, margens crenadas, sem rizinas; superfície superior corticada, acinzentada a esverdeada, lisa, levemente lustrosa, pruína ausente; superfície inferior ecorticada, branca, aracnoide, sem venações; córtex 15-45 $\mu \mathrm{m}$ de espessura; medula 50-110 $\mu \mathrm{m}$ de espessura; picnídios ausentes. Talo secundário: $0,5-3,2 \mathrm{~cm}$ alt., 0,3-1,3 mm de espessura, cinza esbranquiçado, ápices subulados a estreito cifosos, cifas com até $1,2 \mathrm{~mm}$ diâm., nunca ramificadas e geralmente com margens denteadas, simples a raramente ramificado, com até três ramificações na metade superior do podécio, perfurações ausentes, sem base melanótica; superfície ecorticada, algumas vezes com córtex restrito a base do podécio, aracnoide, sorédios e grânulos dispersos por todo o podécio, esquâmulas recortadas com até 1,8 mm compr., localizadas principalmente na metade inferior do podécio; córtex $0-15 \mu \mathrm{m}$ de espessura; medula 30-85 $\mu \mathrm{m}$ de espessura; estereoma 90-170 $\mu \mathrm{m}$ de espessura, hialino, mal delimitado; canal central sulcado e papilado; discos himeniais incomuns, apicais, marrons, 0,3-0,5 mm diâm.; ascósporos ausentes; picnídios incomuns, na margem das cifas, sésseis ou em pequenos pedicelos, marrons, globosos, mucilagem hialina; conídios falciformes, 7-9 × ca. $1 \mu \mathrm{m}$.

Química: Testes de coloração: K-, C-, KC-, KC+ rosa evanescente no quimiotipo IV, UV-. CCD: quatro quimiotipos: I: ácido fumarprotocetrárico; II: ácido fumarprotocetrárico e traços de ácido fisodálico; III: ácido fumarprotocetrárico e uma substância não identificada com Rf C aproximado de 57; IV: ácido fumarprotocetrárico e quatro substâncias não identificadas com RfC aproximados de 35, 42, 56 e 59.

De acordo com Ferraro \& Ahti (1987), C. subradiata é caracterizada pelos podécios esbranquiçados, 1-2 cm alt., abundantemente 
sorediados, raramente ramificados, ápices agudos a estreito cifosos, com pequenas esquâmulas localizadas principalmente na base do podécio.

Cladonia coniocraea é semelhante morfológica e quimicamente a $C$. subradiata. Contudo, as esquâmulas primárias de $C$. coniocraea são sorediadas nas margens inferiores (Burgaz \& Ahti 2009), enquanto que em $C$. subradiata as margens são esorediadas a granulares. Aliado a isso, C. coniocraea é uma espécie holoártica (Ahti 2000, Burgaz \& Ahti 2009).

Cladonia corniculata Ahti \& Kashiw. difere de C. subradiata por ser mais ramificada, com ápices subulados e pelos sorédios caducos, deixando a medula geralmente exposta (Ahti \& Kashiwadani 1984, Ahti 2000).

$\mathrm{Na}$ ausência de discos himeniais, $C$. macilenta Hoffm. pode ser facilmente confundida com C. subradiata uma vez que os podécios são raramente ramificados, ecorticados e abundantemente sorediados (Fleig et al. 1995). No entanto, enquanto em C. macilenta os ápices são subulados e esta produz ácidos tamnólico e/ou barbático (Ahti 2000), em C. subradiata os ápices são geralmente estreito cifosos e há produção de ácidos do grupo fumarprotocetrárico (Ferraro \& Ahti 1987, Fleig et al. 1995, Ahti 2000).

Cladonia polyscypha assemelha-se a C. subradiata pelo podécio ecorticado, sorediado e pela produção de ácido fumarprotocetrárico (ver comentários em C. polyscypha).

Os espécimes da área de estudo possuem ampla variação química, sendo observados sete compostos químicos produzidos como compostos principais, distribuídos em quatro quimiotipos. É relatada pela primeira vez a reação $\mathrm{KC}+$ rosa evanescente, observada no quimiotipo IV, que provavelmente é devida a alguma das substâncias não identificadas.

Cladonia subradiata ocorre desde o nível do mar até 4.200 m.s.m. (Ahti 2000). É muito comum na área de estudo, desenvolvendo-se preferencialmente em áreas bem iluminadas sobre solo e musgos, geralmente entremeadas com C. furfuracea, C. ochracea, C. polystomata Ahti \& Sipman e C. subsquamosa. Quando corticícola ou lignícola, geralmente está próxima ou entremeada com C. ceratophylla (Sw.) Spreng.

Distribuição: Cosmopolita: Oceania (Stenroos 1988), Ásia (Wei 1991), Europa (Aptroot 1989), África (Swinscow \& Krog 1988), América do Norte (Sipman \& Wolf 1998), América Central (Ahti 2000) e América do Sul, na Argentina (Ferraro \& Ahti 1987), Brasil (Osorio 1989), Bolívia (Ahti 2000), Chile (Ahti \& Kashiwadani 1984), Colômbia, Equador (Ahti 2000), Guiana (Sipman \& Aptroot 1992), Guiana Francesa (Ahti 2000), Paraguai (Ferraro \& Ahti 1987), Peru, Suriname e Venezuela (Ahti 2000). Brasil: AC, AM, BA, DF, ES, MG, MS, MT, PA (Ahti 2000), PB, PE (Ahti et al. 1993), PR, RJ, RO, RR (Ahti 2000), RS (Osorio \& Fleig 1990), SC (Ahti 2000), SE (Ahti et al. 1993) e SP (Osorio 1989).

Espécimes examinados selecionados: BRASIL. PARANÁ: Morretes, Serra da Graciosa, 24-VIII-1993, $S$. Eliasaro 1042 (UPCB), ibid. 20-II-2004, R. Reis s.n. (UPCB). Quatro Barras, Serra da Baitaca, Morro Anhangava, $25^{\circ} 23^{\prime} \mathrm{S}$ e $49^{\circ} 00^{\prime} \mathrm{W}, 1.420$ m.s.m., 14-VII-2011, A.M. Charnei et al. 251, 254, 274 (UPCB). Guaratuba, Serra do Araçatuba, Morro dos

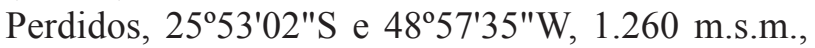
31-VIII-2002, S. Eliasaro 2378, 2383 (UPCB), ibid. 15-IV-2011, A.M. Charnei et al. 56 (UPCB). SANTA CATARINA: Campo Alegre, Serra do Quiriri, 2600'52"S e 4900'39"W, 900 m.s.m., 26-XII-2011,E. Gumboski \& F. Beilke 3239 (UPCB). Joinville, Serra Queimada, 2607'14"S e 4902'46"W, 1.240 m.s.m., 4-IX-2011, A.M. Charnei \& F. Beilke 433 (UPCB); Serra Dona Francisca, 900 m.s.m., 4-V-2010, F. Beilke et al. 3, 31, 33, 55, 77 (UPCB).

11. Cladonia subsquamosa Kremp., in Warming, Vidensk.Meddel.DanskNaturhist.Foren. Kjøbenhavn 5: 366, 1873.

Figura 11

Talo primário: persistente a evanescente, composto por inconspícuas esquâmulas lobadas, recortadas, 0,4-1,2 mm compr., 0,7-2 mm larg., sorédios e grânulos ausentes, margens principalmente lisas a ocasionalmente crenadas, sem rizinas; superfície superior corticada, esverdeada, lisa, tenuamente lustrosa, pruína ausente; superfície inferior ecorticada, branca, aracnoide, sem venações; córtex 10-20 $\mu \mathrm{m}$ de espessura; medula 25-50 $\mu \mathrm{m}$ de espessura; picnídios ausentes. Talo secundário: 0,4-2,5 cm alt., 0,5-1,5 mm de espessura, esverdeado a acinzentado, regularmente cifoso, cifas com até $4 \mathrm{~mm}$ diâm., com até três cifas sobrepostas que se originam na margem, raramente a partir do centro da cifa, margens das cifas levemente a profundamente denteadas, ápices capitados em podécios férteis, base não melanótica, perfurações ausentes; superfície geralmente totalmente ecorticada a raramente corticada na base do podécio, sorediada, 
sorédios geralmente caducos, expondo a medula e/ou o estereoma, grânulos presentes principalmente dentro das cifas e em podécios férteis, esquâmulas laciniadas, recortadas, com margens lisas a crenadas, com até 1,2 mm compr., principalmente na base do podécio; medula (0-)50-70 $\mu \mathrm{m}$ de espessura; estereoma 120-240 $\mu \mathrm{m}$ de espessura, mal delimitado, hialino a levemente amarronzado; canal central liso; discos himeniais frequentes, em pequenas ramificações na margem das cifas, marrons claros a marrons enegrecidos, com até $1,7 \mathrm{~mm}$ diâm.; ascósporos ausentes; picnídios frequentes, nas margens das cifas, marrons, globosos a piriformes, mucilagem hialina; conídios levemente curvados a falciformes, $7-8(-9) \times$ ca. $1 \mu \mathrm{m}$.

Química: Testes de coloração: K-, C-, KC-, UV-. CCD: ácido fumarprotocetrárico.

Nesta espécie os podécios são regularmente cifosos, às vezes com duas ou mais cifas originadas na margem, sobrepostas, a superfície é ecorticada, sorediada e com esquâmulas localizadas principalmente na metade inferior do podécio e há produção de ácido fumarprotocetrárico (Fleig et al. 1995, Ahti 2000).

Cladonia fimbriata difere de C. subsquamosa pelas margens das cifas espessadas e pelos sorédios frequentemente aderidos à superfície do podécio, não expondo a medula e/ou o estereoma, ao passo que em $C$. subsquamosa as margens das cifas não são espessadas e a medula e/ou o estereoma geralmente são expostos, uma vez que seus sorédios são caducos (Ahti 2000, Burgaz \& Ahti 2009).

Cladonia chlorophaea assemelha-se morfológica e quimicamente a C. subsquamosa (ver comentários em C. chlorophaea).

É uma das espécies mais comuns da área de estudo, dado também relatado por Gumboski \& Eliasaro (2012) para costões rochosos e restingas dos Estados do Paraná e Santa Catarina, tendo sido encontrada em vários substratos: solo, musgos, restos vegetais em decomposição, fina camada de sedimentos sobre rocha e base de árvores. Foi encontrada desenvolvendo-se isoladamente ou entremeada com outras espécies como C. ceratophylla, $C$. furfuracea e C. subradiata.

Distribuição: Cosmopolita: Oceania (Vainio 1887), Ásia (Wei 1991), Europa (Crombie 1883), África (Swinscow \& Krog 1988), América do Norte (Fink 1919), América Central (Ahti 2000) e América do Sul (Crombie 1876), na Argentina (Vainio 1903), Brasil
(Osorio \& Fleig 1989), Bolívia (Ahti 2000), Chile (Crombie 1876), Colômbia, Equador (Ahti 2000), Guiana (Sipman \& Aptroot 1992), Paraguai, Peru, Uruguai (Ahti 2000) e Venezuela (Lopez-Figueiras 1986). No Brasil é registrada para os Estados da BA, ES, GO, MG (Ahti 2000), PB, PE (Ahti et al. 1993), PR, RJ (Ahti 2000), RS (Osorio \& Fleig 1989), SC (Ahti 2000), SE (Ahti et al. 1993) e SP (Marcelli 1990).

Espécimes examinados: BRASIL. PARANÁ: Campina Grande do Sul, Serra do Ibitiraquiri, Morro do Getúlio, $25^{\circ} 14^{\prime}$ S e $48^{\circ} 50^{\prime} \mathrm{W}, 1.230$ m.s.m., 6-VII-2011, A.M. Charnei et al. 147, 153 (UPCB). Morretes, Serra da Graciosa, 17-VII-1999, S. Eliasaro s. n. (UPCB). Quatro Barras, Serra da Baitaca, Morro Anhangava, $25^{\circ} 23^{\prime} \mathrm{S}$ e $49^{\circ} 00^{\prime} \mathrm{W}, 900$ m.s.m., 14-VII-2011, A.M. Charnei et al. 290 (UPCB). Piraquara, Serra Marumbi, Morro do Canal, 22-V-2002, S. Eliasaro 2252 (UPCB). Guaratuba, Serra do Araçatuba,

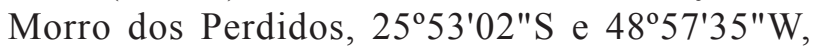
1.260 m.s.m., 15-IV-2011, A.M. Charnei et al. 07 (UPCB). SAnta Catarina: Joinville, Serra Dona Francisca, 900 m.s.m., 4-V-2010, F. Beilke et al. 132, 141 (UPCB); Castelo dos Bugres, 26 $6^{\circ} 13^{\prime} \mathrm{S}$ e $49^{\circ} 03^{\prime} \mathrm{W}$, 998 m.s.m., 12-VIII-2011, A.M. Charnei et al. 409 (UPCB); Serra Queimada, 260 $07^{\prime} 14^{\prime \prime S}$ e 49 $02^{\prime} 46^{\prime \prime} \mathrm{W}$, 1.240 m.s.m., 4-IX-2011, A.M. Charnei \& F. Beilke 435, 440 (UPCB). Santo Amaro da Imperatriz, Pico da Serra do Tabuleiro, $27^{\circ} 49^{\prime} \mathrm{S}$ e $48^{\circ} 53^{\prime} \mathrm{W}, 1.250$ m.s.m., 13-VIII-2011, A.M. Charnei et al. 321, 336 (UPCB).

\section{Agradecimentos}

As Autoras agradecem aos biólogos Alice Gerlach, Emerson Gumboski, Flávio Beilke, Vanessa Ariati e Vitor de Freitas Batista, pelo auxílio nas coletas. Aos curadores dos herbários ICN e MBM, pelo empréstimo dos espécimes solicitados. Aos órgãos ambientais estaduais Fundação do Meio Ambiente (FATMA) e Instituto Ambiental do Paraná (IAP), pelas licenças de coleta concedidas. Ana Márcia Charnei agradece a CAPES (Coordenadoria de Aperfeiçoamento Pessoal do Ensino Superior), pela concessão de bolsa de Mestrado.

\section{Literatura citada}

Ahti, T. 2000. Cladoniaceae. Flora Neotropica 78. Organization for Flora Neotropica and New York Botanical Garden, New York. 
Ahti, T. \& Kashiwadani, H. 1984. The lichen genera Cladia, Cladina and Cladonia in Southern Chile. In: H. Inoue (ed.). Studies on cryptogams in Southern Chile. Tokyo, Kenseisha Ltd., pp. 125-151.

Ahti, T., Stenroos, S. \& Xavier Filho L. 1993. The lichen family Cladoniaceae in Paraiba, Pernambuco and Sergipe, Northeast Brazil. Tropical Bryology 7: 55-70.

Ahti, T. \& Hammer, S. 2002. Cladonia. In: Nash III, T. H.; Ryan, B. D.; Gries, C.\& Bungartz, F. Lichen Flora of the Greater Sonoran Desert Region. Arizona State University, v. 1., pp. 131-158.

Aptroot, A. 1989. Contribution to the Azores lichen flora. Lichenologist 22: 59-65.

Brodo, I.M. \& Ahti, T. 1996. Lichens and lichenicolous fungi of the Queen Charlotte Islands, British Columbia, Canada. Canadian Journal of Botany 74: 1147-1180.

Brodo, I.M., Sharnoff, S. D. \& Sharnoff, S. 2001. Lichens of North America, New Haven and London, Yale University Press.

Burgaz, A.R. \& Ahti, T. 2009. Cladoniaceae. Flora Liquenológica Ibérica. Volume 4. Sociedad Española de Liquenología (SEL), Madrid.

Calvelo, S. \& Liberatore, S. 2002. Catálogo de los líquenes de la Argentina (Checklist of Argentinean Lichens). Kurtziana 29: 7-170.

Charnei, A.M. \& Eliasaro, S. 2013a. Notes on the chemical variation of the lichenized Ascomycota Cladia aggregata (Cladoniaceae) in the States of Paraná and Santa Catarina, Brazil. Acta Botanica Brasilica 27: 624-625.

Charnei, A.M. \& Eliasaro. S. 2013b. Verticillate Cladonia species (Lichenized Ascomycota) from high-altitude environments on the Serra do Mar Mountain in Southern Brazil. Hoehnea 40: 87-97.

Culberson, C.F. \& Ammann, K. 1979. Standard method zur Dünnschicht chomatographie von Flechtensubstanzen. Herzogia 5: 1-24.

Crombie, J.M. 1876. On the lichens collected by Prof. R. O. Cunningham in the Falkland Islands, Fuegia, Patagonia and the Island of Chile during the voyage of H. M. S. Nassau 1867-1869. Journal Linnean Society 15: 222.

Crombie, J.M. 1883. Enumeration of the British Cladoniei. Grevillea 11: 111-115.

Doidge, E.M. 1950. The South African fungi and lichens to the end of 1945. Bothalia 5: 1-1094.

Eliasaro, S., Gerlach, A.C.L. \& Gumboski, E.L. 2012. Novos registros de fungos liquenizados para o Estado do Paraná, Brasil. Revista Brasileira de Biociências 10: $507-512$

Elix, J.A. \& Ernst-Russell, K.D. 1993. A Catalogue of Standardized Thin Layer Chromatographic Data and Biosynthetic Relationships for Lichen Substances $2^{\text {nd }}$ ed. Australian National University Camberra.
Ferraro, L.I. \& Ahti, T. 1987. Contribución al conocimiento del gênero Cladonia (Cladoniaceae - Liquenes) de Argentina y regiones limítrofes. Bonplandia 6: 57-69.

Feuerer, T., Ahti, T \& Vitikainen, O. 1998. Lichenological investigations in Bolivia. In: M.P. Marcelli \& M.R.D. Seaward (eds). Lichenology in Latin America: History, current knowledge and applications CETESB, São Paulo, pp. 71-86.

Fink, B. 1919. Additions to lichen distribution in Noth America. Mycologia 11: 296-307.

Fleig, M., Ahti, T. \& Stenroos, S. 1995. A família Cladoniaceae (liquens) no Rio Grande do Sul, Brasil. Napaea 11: 1-29.

Galloway, D.J. 1985. Flora of New Zealand. Lichens. Wellington New Zealand.

Gumboski, E.L. \& Eliasaro, S. 2011. Checklist of lichenized fungi of Santa Catarina State (Brazil). Mycotaxon 115: 535.

Gumboski, E.L. \& Eliasaro, S. 2012. Espécies de Cladonia P. Browne (Cladoniaceae, Ascomycota) do Supergrupo Cladonia em restingas e costões rochosos dos Estados do Paraná e de Santa Catarina, Brasil. Hoehnea 39: 315-337.

Gumboski, E.L., Beilke, F. \& Eliasaro, S. 2013. Cladonia dunensis sp. nov. from southern Brazil, with notes on the genus in beach dune environments. Mycotaxon 124: 333-340.

Holien, H. 2005. Additions to the Norwegian flora of lichens and lichenicolous fungi III. Graphis Scripta 17: 62-64.

Howard, G.E. 1950. Lichens of the State of Washington. Seattle. University of Washington Press.

Kashiwadani, H. 1975. Cladonia multiformis Merr. Found in Japan. Journal of Japanese Botany 50: 352.

Krog, H. 1968. The Macrolichens of Alaska. Norsk Polarinstitut. Oslo, Norway.

Lopez-Figueiras, M. 1986. Censo de macroliquenes Venezolanos de los Estados Falcon, Lara, Merida, Tachira y Trujillo. Universidad de Los Andes. Merida.

Marcelli, M.P. 1990. Liquens das Restingas e Manguezais da Ilha do Cardoso. In: II Simpósio de Ecossistemas da Costa Sul Sudeste Brasileira: estrutura, função e manejo. Águas de Lindóia, São Paulo, pp. 382-292.

McCune, B \& Geiser, L. 1997. Macrolichens of the Pacific Northwest. Oregon State University Press.

Merrill, G.K. 1909. Lichen notes n. 7. Cladonia multiformis (nom. nov.) Bry. 6: 1908. The Bryologist 12: 1-5.

Müller, J. 1981. Lichenes Catharinenses a cl. E. Ule in Brasilia prov. Santa Catharina lecti. Hedwigia 30: $235-243$.

Osorio, H.S. 1972. Contibution to the lichen flora of Uruguai. VII. A preliminary catalogue. Comunicaciones Botánicas Del Museo de Historia Natural de Montevideo 4: 1-46. 
Osorio, H.S. 1989. Contribution to the lichen flora of Brazil. XXIII. Lichens from São Paulo City. Mycotaxon 36: 161-162.

Osorio, H.S. \& Fleig, M. 1988. Contribution to the lichen flora of Brazil. XX. Additional records from São Francisco de Paula, Rio Grande do Sul State. Comunicaciones Botánicas Del Museo de Historia Natural de Montevideo 5: 1-7.

Osorio, H.S. \& Fleig, M. 1989. Contribution to the lichen flora of Brazil. XXV. Lichens from Parque Náutico, Santa Maria, Rio Grande do Sul State. Comunicaciones Botánicas Del Museo de Historia Natural de Montevideo 5: 1-4.

Osorio, H.S. \& Fleig, M. 1990. Contribution to the lichen flora of Brazil. XXVI. Lichens from Vale do Diabo, Rio Grande do Sul State. Comunicaciones Botánicas del Museo de Historia Natural de Montevideo 5: 16.

Osorio, H.S. \& Fleig, M. 1991. Contribution to the lichen flora of Brazil. XXVIII. Lichens from northern Santa Maria, Rio Grande do Sul State. Comunicaciones Botánicas del Museo de Historia Natural de Montevideo 5: 1-7.

Øvstedal, D.O. \& Smith, R.I.L. 2001. Lichens of Antarctida and South Georgia. A guide to their identification and ecology. Studies in polar Research, Cambridge University Press, Cambridge.

Sipman, H.J. M. \& Aptroot, A. 1992. Results of a botanical expedition to Mount Roraima, Guyana. II. Lichens. Tropical Bryology 5: 79-108.

Sipman, H.J. M. \& Wolf, J.H.D. 1998. Provisional checklist of the lichens of Chiapas. Acta Botánica Mexicana 45: 1-29.
Stenroos, S. 1988. The family Cladoniaceae in Melanesia. 3. Cladonia sections Helopodium, Perviae and Cladonia. Annales Botanici Fennici 25: 117-148.

Stenroos, S., Hyvonen, J., Myllys, L., Thell, A. \& Ahti, T. 2002. Phylogeny of the genus Cladonia s.lat. (Cladoniaceae, Ascomycetes) inferred from molecular, morphological, and chemical data. Cladistics 18: 237-278.

Swinscow, T.D.V. \& Krog, H. 1988. Macrolichens of East Africa. British Museum (Natural History), London.

Taylor, C.J. 1967. The lichens of Ohio. Part I. Foliose lichens. The Ohio Biological Survey, The Ohio State University Press, Columbia.

Taylor, C.J. 1968. The lichens of Ohio. Part II. Fruticose lichens. The Ohio Biological Survey, The Ohio State University Press, Columbia.

Vainio, E.A. 1887. Monographia Cladoniarum Universalis. I. Acta Societatis pro Flora et Fauna Fennica, v. 4.

Vainio, E.A. 1894. Monographia Cladoniarum Universalis. II. Acta Societatis pro Flora et Fauna Fennica, v. 10.

Vainio, E.A. 1903. Expédition Antarctique Belge. Résultats du Voyage du S. Y. Belgica en 1897-1898-1899. J. E Buschmann. Belgium.

Wang, X.Y., Joshi, Y. \& Hur, J.S. 2011. The genus Cladonia (lichenized Ascomycota, Cladoniaceae) in South Korea. Mycotaxon 117: 405-422.

Wei, J.C. 1991. Cladina and Cladonia. An enumeration of lichens in China. International Academic Publishers, Beijing, China. pp. 62-82. 